02

\title{
Люминесценция полимерной композиции, допированной хелатами бора. Механизм сенсибилизации люминесценции
}

\author{
(C) А.А. Хребтов ${ }^{1}$, Е.В. Федоренко ${ }^{2}$, Л.А. Лим ${ }^{1}$, В.А. Реутов ${ }^{1}$ \\ ${ }^{1}$ Дальневосточный федеральный университет, \\ 690091 Владивосток, Россия \\ ${ }^{2}$ Институт химии Дальневосточного отделения РАН, \\ 690022 Владивосток, Россия \\ e-mail: xrebtov_aa@students.dvfu.ru
}

Поступила в редакцию 23.08.2017 г.

Обнаружено, что в системе дибензоилметанатдифторида бора $\left(\mathrm{DBMBF}_{2}\right)$ - антраценоилацетонат дифторида бора $\left(\mathrm{AntAcBF}_{2}\right)$ в полистирольной матрице наблюдается сенсибилизированная люминесценция $\mathrm{Ant}_{\mathrm{AcBF}}$. Установлен излучательный механизм переноса энергии от $\mathrm{DBMBF}_{2}$ к AntAcBF 2 . Исследованы люминесцентные свойства двуслойных пленок, один слой которых содержит $\mathrm{DBMBF}_{2}$, второй $-\mathrm{Ant}_{\mathrm{AcBF}}$. При содержании люминофоров в эквимолярных количествах наблюдается белая люминесценция двуслойной полимерной композиции.

DOI: $10.21883 /$ OS.2018.01.45360.186-17

\section{Введение}

$\beta$-Дикетонаты дифторида бора отличаются яркой люминесценцией как в кристаллическом состоянии, так и в растворах [1]. $\beta$-Дикетонаты дифторида бора при высоких концентрациях способны образовывать эксимеры (димеры и тримеры) в растворах [2,3] и в полимерной матрице [4], что значительно повышает фотостойкость красителя [5]. Люминесценция эксимеров отличается значительным батохромным смещением спектра люминесценции относительно спектра поглощения люминофора, что позволяет уменьшить потери энергии в результате самопоглощения. Возможно также образование эксиплексов в результате взаимодействия молекул люминофора с ароматическими группами соседних молекул [6]. Как показано в [3], изменяя концентрацию раствора $\beta$-дикетонатов дифторида бора можно управлять цветом люминесценции. $\beta$-Дикетонаты дифторида бора способны образовывать ярко люминесцирующие агрегаты, возбуждение которых происходит на длинноволновом краю спектра поглощения [7].

Получение и исследование органических белых люминофоров является важным направлением современной науки благодаря развитию техники на основе светоизлучающих диодов, где наиболее широко применяются данные вещества [8-10]. К числу перспективных веществ для данного приложения относятся $\beta$-дикетонаты дифторида бора, которые способны излучать белый свет в растворах как одиночных веществ [3], так и в составе композиций люминофоров, где они выступают в качестве голубой компоненты [11].

Поведение люминофоров в полимерной матрице отличается от такового в кристаллическом состоянии и растворах благодаря различным формам агрегации, межмолекулярного взаимодействия и кристаллизации [10], поэтому представляет интерес исследование люминесцен- ции полимерных композиций, допированных $\beta$-дикетонатами дифторида бора.

Настоящая работа посвящена исследованию процесса межмолекулярного переноса энергии между дибензоилметанатом дифторида бора $\left(\mathrm{DBMBF}_{2}\right)$, обладающим синей люминесценцией, и другим представителем данного класса соединений - антраценоилацетонатом дифторида бора $\left(\mathrm{Ant}_{\mathrm{AcBF}}\right)$, обладающим желто-зеленой люминесценцией. Структурные формулы этих соединений приведены на схеме.<smiles>CCCCCC(C)(C)C</smiles>

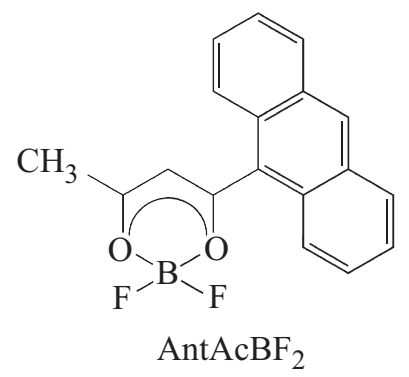

\section{Экспериментальная часть}

Соединение $\mathrm{DBMBF}_{2}$ получено по методике [12], $\mathrm{AntAcBF}_{2}$ - по методике [13]. Пленки (толщина $0.03 \mathrm{~mm}$ ) на основе полистирола (ПС) с $0.2 \mathrm{wt} . \%$ $\mathrm{AntAcBF}_{2}$, с 0.2 wt.\% $\mathrm{DBMBF}_{2}$ и с мольным соотношением AntAcBF $2: \mathrm{DBMBF}_{2} 1: 2,1: 1,1: 0.5,1: 0.25$ и $1: 0.1$ (концентрация AntAcBF 2 в этих пленках - 0.2 wt.\%) получены методом формования из раствора $1 \mathrm{~g}$ ПС и точных навесок $\mathrm{DBMBF}_{2}$ и $\mathrm{AntAcBF}_{2}$ в $20 \mathrm{ml}$ толуола в чашке Петри после высушивания в течение $24 \mathrm{~h}$ в закрытой камере. 
Аналогично были получены тонкие (А) (порядка $0.05 \mathrm{~mm}$ ) и толстые (В) (порядка $0.2 \mathrm{~mm}$ ) пленки с $\mathrm{DBMBF}_{2}$ и с $\mathrm{AntAcBF}_{2}$ на основе ПС. Пленки с $\mathrm{DBMBF}_{2}$ и AntAcBF 2 были склеены прессованием при температуре $90^{\circ} \mathrm{C}$, в результате чего были получены двухслойные пленки (каскады 1) А-A, А-B, В-А и В-В соответственно.

Методом пневмонапыления на стеклянную подложку растворов были получены двухслойные пленки на стекле (каскады 2), нижний слой которых допирован 0.2 wt.\% $\mathrm{DBMBF}_{2}$, верхний - 0.2 wt.\% AntAcBF 2 . Пневмонапыление растворов $1 \mathrm{~g}$ ПС и навесок соответствующих люминофоров в $20 \mathrm{ml}$ толуола проводили последовательно, соотношение общей толщины пленки с $\mathrm{DBMBF}_{2}$ к пленке с AntAcBF 2 в каскадах 2 составило 1:1, 1:2, $2: 1$ и $2: 2$. Например, алгоритм получения каскада 2 с соотношением толщин 2:1 состоял из следующих стадий: нанесение первого слоя пленки с $\mathrm{DBMBF}_{2}$, его высушивание в закрытой камере при комнатной температуре, нанесение второго слоя с $\mathrm{DBMBF}_{2}$, высушивание, нанесение слоя с $\mathrm{Ant}_{\mathrm{AcBF}}$ с последующим высушиванием. Таким образом, общая толщина слоя с $\mathrm{DBMBF}_{2}$ в 2 раза превышает толщину слоя с AntAcBF 2 .

Спектры возбуждения люминесценции и люминесценции регистрировали на спектрофлуориметре Shimadzu RF5301. Времяразрешенные спектры измерены на лазерном пикосекундном спектрофлуориметре FluoTime 200 (PicoQuant), источник PDL 800-B ( $\left.\lambda_{\mathrm{ex}}=370 \mathrm{~nm}\right)$. Спектры поглощения регистрировали на спектрометре Shimadzu UV-2550.

\section{Результаты и обсуждение}

На рис. 1 представлены спектры возбуждения люминесценции и люминесценции ПС-пленок, допированных $\mathrm{DBMBF}_{2}$ и AntAcBF 2 . В спектре возбуждения люминесценции $\mathrm{DBMBF}_{2}$ в ПС наблюдается широкая полоса в

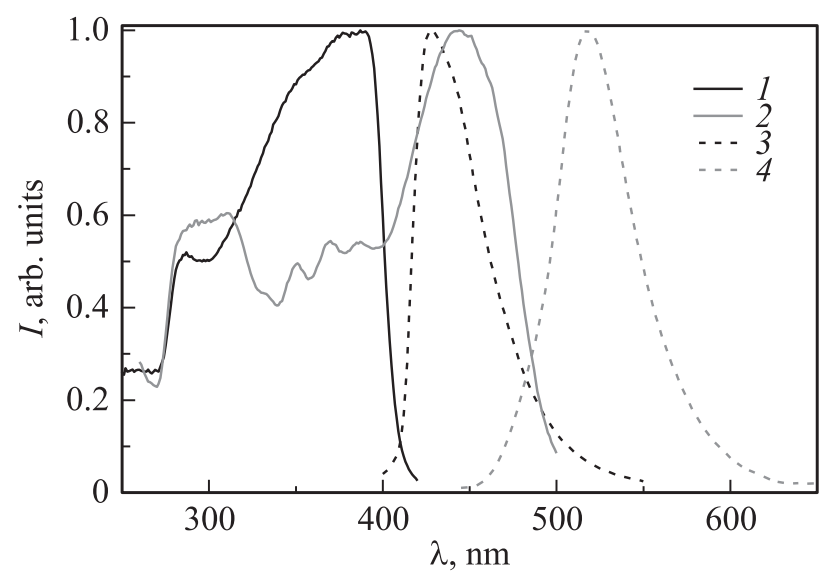

Рис. 1. Спектры возбуждения люминесценции ПС-пленок с $\mathrm{DBMBF}_{2}$ (1) и AntAcBF 2 (2) и люминесценции ПС-пленок с $\mathrm{DBMBF}_{2}$ (3) и $\mathrm{AntAcBF}_{2}(4)$.

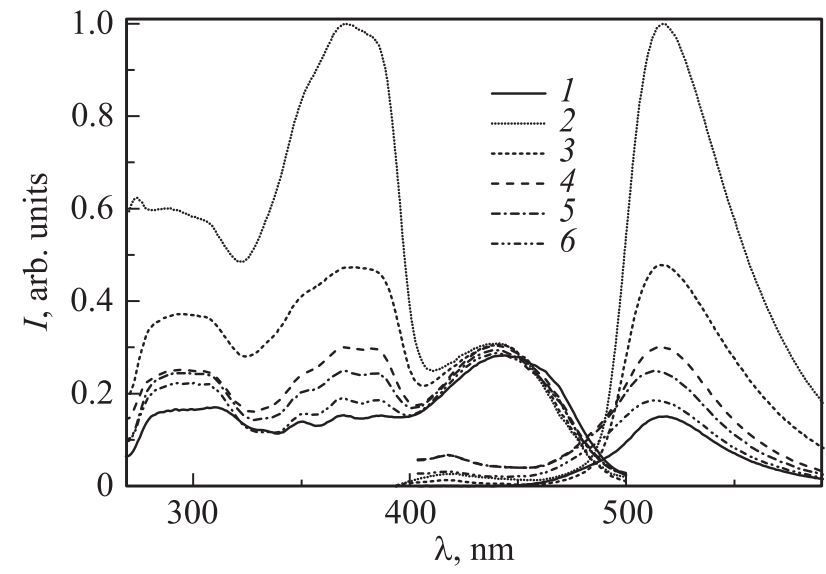

Рис. 2. Спектры возбуждения люминесценции (слева, $\lambda_{\text {рег }}=515 \mathrm{~nm}$ ) и спектры люминесценции (справа, $\left.\lambda_{\text {возб }}=380 \mathrm{~nm}\right)$ ПС-пленок с $0.2 \mathrm{wt} . \% \operatorname{AntAcBF}_{2}(1)$, с мольным соотношением AntAcBF 2 : $\mathrm{DBMBF}_{2}$ 1:2 (2), 1:1 (3), 1:0.5 (4), $1: 0.25(5)$ и $1: 0.1(6)$.

области 330-400 nm с максимумом $377 \mathrm{~nm}$, максимум спектра люминесценции составляет $430 \mathrm{~nm}$, что соответствует голубой люминесценции пленки. В спектре возбуждения люминесценции AntAcBF 2 в ПС наблюдаются интенсивная длинноволновая полоса с максимумом $440 \mathrm{~nm}$ и ряд низкоинтенсивных полос в области 300-400 nm, соответствующих электронным переходам антраценового заместителя [14], максимум спектра люминесценции составляет $515 \mathrm{~nm}$, что соответствует желто-зеленому цвету люминесценции.

Из рис. 1 видно, что спектр люминесценции $\mathrm{DBMBF}_{2}$ перекрывается с длинноволновой полосой спектра возбуждения люминесценции $\mathrm{AntAcBF}_{2}$, это позволяет предположить наличие сенсибилизированной люминесценции в системе $\mathrm{DBMBF}_{2}-\mathrm{Ant}_{\mathrm{AcBF}}-\Pi \mathrm{C}$.

Действительно, при возбуждении пленок со смесью AntAcBF 2 и $\mathrm{DBMBF}_{2}$ светом с длинной волны $380 \mathrm{~nm}$ наблюдается увеличение интенсивности полосы люминесценции $515 \mathrm{~nm}$ с повышением концентрации $\mathrm{DBMBF}_{2}$ (рис. 2), причем при мольном соотношении $\mathrm{AntAcBF}_{2}: \mathrm{DBMBF}_{2}$ 1:1 интенсивность люминесценции полимерной композиции в 3 раза выше, чем для пленки, содержащей только AntAcBF 2 , и в спектре люминесценции композиции отсутствует полоса люминесценции $\mathrm{DBMBF}_{2} 430 \mathrm{~nm}$.

На рис. 2 приведены спектры возбуждения люминесценции композиций с различным мольным соотношением AntAcBF $2: \mathrm{DBMBF}_{2}$ в сравнении со спектром AntAcBF 2 в ПС, записанные при длине волны регистрации $515 \mathrm{~nm}$, соответствующей люминесценции AntAcBF 2 . Для пленки, содержащей только AntAcBF 2 , интенсивность полосы с максимумом $440 \mathrm{~nm}$ имеет максимальное значение. При добавлении $\mathrm{DBMBF}_{2}$ интенсивность группы полос в области $300-400 \mathrm{~nm}$ возрастает и становится сравнимой с полосой $440 \mathrm{~nm}$. При 


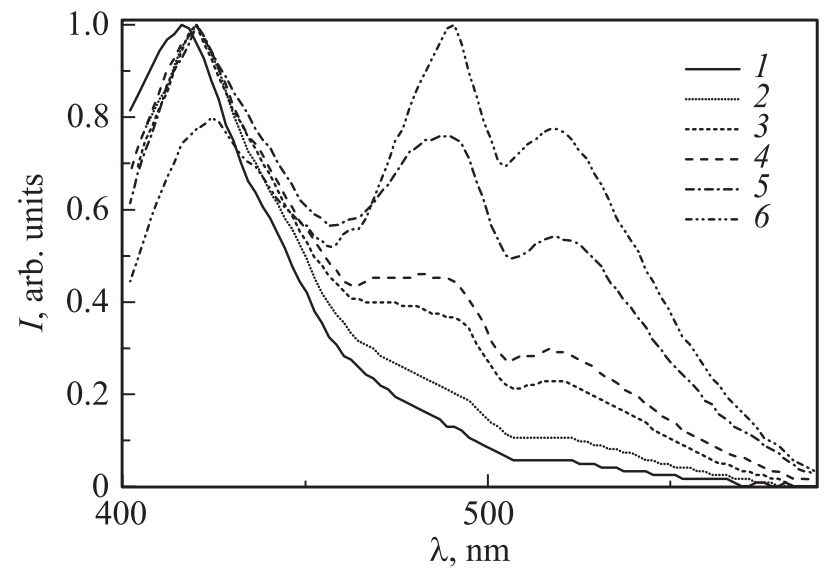

Рис. 3. Разрешенные во времени спектры люминесценции $\left(\lambda_{\text {возб }}=380 \mathrm{~nm}\right)$ пленки с мольным соотношением AntAcBF : $\mathrm{DBMBF}_{2} 1: 1$ : время с момента возбуждения 0 (1), 0.5 (2), 1.2 (3), $1.4(4), 2.3$ (5) и $3.2 \mathrm{~ns}(6)$.

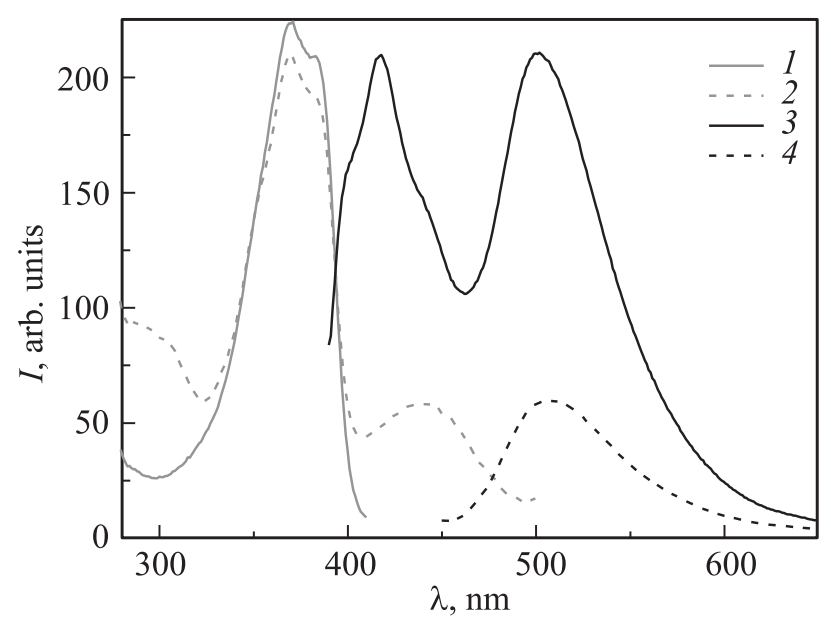

Рис. 4. Спектры возбуждения люминесценции при $\lambda_{\text {рег }}=420 \mathrm{~nm} \quad(1), \quad \lambda_{\text {рег }}=515 \mathrm{~nm} \quad$ (2) и люминесценции при $\quad \lambda_{\text {возб }}=380 \mathrm{~nm} \quad(3), \quad \lambda_{\text {возб }}=440 \mathrm{~nm} \quad$ (4) каскада 2 с соотношением толщин $1: 1$.

низких концентрациях $\mathrm{DBMBF}_{2}$ сохраняется структуpa полосы, характерная для спектра AntAcBF 2 в ПС (рис. 1). При мольном соотношении $\mathrm{AntAcBF}_{2}: \mathrm{DBMBF}_{2}$ $1: 0.5$ интенсивность полос 377 и $440 \mathrm{~nm}$ выравнивается, при дальнейшем увеличении концентрации $\mathrm{DBMBF}_{2}$ ocновной вклад в возбуждение люминесценции $\mathrm{AntAcBF}_{2}$ вносит полоса $377 \mathrm{~nm}$, при этом ее интенсивность значительно выше, чем полосы $440 \mathrm{~nm}$ (рис. 2). Из полученных спектральных данных видно, что в системе $\mathrm{DBMBF}_{2}-\mathrm{Ant}_{\mathrm{AcBF}}-$ ПС наблюдается сенсибилизированная люминесценция AntAcBF 2 (акцептор энергии), донором энергии является $\mathrm{DBMBF}_{2}$, поглощающий в коротковолновой области.

Дополнительные данные получены методом времяразрешенной люминесцентной спектроскопии пленки с мольным соотношением AntAcBF $2: \mathrm{DBMBF}_{2}$ 1:1 (рис. 3). В начальный момент времени регистрируется полоса люминесценции $\mathrm{DBMBF}_{2}(420 \mathrm{~nm})$, и только через $0.5 \mathrm{~ns}$ появляются полосы, соответствующие люминесценции $\mathrm{AntAcBF}_{2}$ (490 и $523 \mathrm{~nm}$ ). Это также свидетельствует об излучательном механизме передачи энергии от донора $\left(\mathrm{DBMBF}_{2}\right)$ к акцептору $\left(\mathrm{Ant} \mathrm{AcBF}_{2}\right)$.

Излучательный механизм сенсибилизации люминесценции может быть наглядно продемонстрирован на двуслойных пленках (каскадах 1). При расположении каскадов 1 слоем, содержащим $\mathrm{DBMBF}_{2}$, к детектору возбуждающий свет $(380 \mathrm{~nm})$ поглощается в поверхностном слое, и в спектре люминесценции наблюдается только полоса $430 \mathrm{~nm}$, соответствующая эмиссии $\mathrm{DBMBF}_{2}$. $\mathrm{B}$ растворе $\mathrm{DBMBF}_{2}$ обладает более высокой поглощающей способностью, чем AntAcBF 2 : в хлороформе при $380 \mathrm{~nm} \lg \varepsilon$ равен 4.23 и 3.68 соответственно. При расположении каскадов 1 слоем, содержащим AntAcBF 2 , к детектору при $\lambda_{\text {возб }}=380 \mathrm{~nm}$ возбуждающий свет достигает второго слоя, допированного $\mathrm{DBMBF}_{2}$, и в спектре люминесценции наблюдается два максимума 430 и $515 \mathrm{~nm}$. Поэтому дальнейшую регистрацию спектров люминесценции проводили при расположении каскадов 1 слоем, содержащим AntAcBF 2 , к детектору. В спектре люминесценции образцов $\mathrm{A}-\mathrm{A}, \mathrm{A}-\mathrm{B}$ и $\mathrm{B}-\mathrm{B}$ наблюдается высокоинтенсивная полоса $515 \mathrm{~nm}$, что свидетельствует об излучательном переносе энергии от $\mathrm{DBMBF}_{2}$ к AntAcBF 2 . Для образца B-A, у которого толщина слоя с $\mathrm{DBMBF}_{2}$ больше, наблюдается суммарный спектр люминесценции $\mathrm{DBMBF}_{2}$ и $\mathrm{AntAcBF}_{2}$ в области от 410 до $570 \mathrm{~nm}$ с двумя максимумами (430 и $515 \mathrm{~nm}$ ), который визуально выглядит как белое свечение.

Аналогичная зависимость наблюдается и для каскадов 2, полученных напылением раствора ПС и люминофора на стеклянную подложку. На рис. 4 представлена зависимость спектра люминесценции каскада 2 с соотношением толщин 1:1 от длины волны возбуждающего света и спектра возбуждения люминесценции от длины волны регистрации. Следует отметить, что при $\lambda_{\text {возб }}=380 \mathrm{~nm}$ интенсивность полосы люминесценции с максимумом $515 \mathrm{~nm}$ значительно выше, чем при $\lambda_{\text {возб }}=440 \mathrm{~nm}$ (рис. 4); одновременно в спектре возбуждения люминесценции при $\lambda_{\text {рег }}=515 \mathrm{~nm}$ наблюдается отчетливая полоса, соответствующая возбуждению $\mathrm{DBMBF}_{2}$ (рис. 4). Таким образом, для двуслойных пленок также наблюдается эффективная сенсибилизация люминесценции AntAcBF 2 донором $\mathrm{DBMBF}_{2}$.

\section{Выводы}

Нами проведено исследование влияния люминесценции $\mathrm{DBMBF}_{2}$ на спектральные свойства AntAcBF 2 в ПС-матрице. Полученные данные свидетельствуют, что передача энергии от $\mathrm{DBMBF}_{2}$ (донор) к $\mathrm{AntAcBF}_{2}$ (акцептор) происходит по излучательному механизму, область испускания донора и возбуждения люминесценции акцептора перекрываются. 
В двуслойных полимерных композициях также наблюдается излучательный перенос энергии от донора к акцептору. При сравнимых толщинах слоев, допированных $\mathrm{DBMBF}_{2}$ и $\mathrm{AntAcBF}_{2}$ с одинаковой концентрацией, при возбуждении светом с длиной волны $380 \mathrm{~nm}$ наблюдается белая люминесценция каскадов. Полученные двуслойные полимерные композиции могут быть использованы для разработки светодиодов с белым свечением.

\section{Список литературы}

[1] Буквецкий Б.В., Федоренко Е.В., Мирочник А.Г. // Изв. АН. Сер. хим. 2013. № 9. С. 1991; Bukvetskii B.V., Fedorenko E.V., Mirochnik A.G. // Russ. Chem. Bull., Int. Ed., 2013. V. 62. N 9. P. 1991. doi 10.1007/s11172-013-0289-5

[2] Мирочник А.Г., Буквецкий Б.В., Гухман Е.В., Жихарева П.А., Карасев В.Е. // Изв. АН. Сер. хим. 2001. № 9. C. 1535; Mirochnik A.G., Bukvetskii B.V., Gukhman E.V., Zhikhareva P.A., Karasev V.E. // Russ. Chem. Bull., Int. Ed., 2013. V. 50. N 9. P. 1612.

[3] Sakai A., Tanaka M., Ohta E., Yoshimoto Y., Mizuno K., Ikeda H. // Tetrahedron Lett. 2012. V. 53. N 32. P. 4138. doi 10.1016/j.tetlet.2012.05.122

[4] Schmidt T.M., Bochenkov V.E., Espinoza J.D.A., Smits E.C.P., Muzafarov A.M., Kononevich Y.N., Sutherland D.S. // J. Phys. Chem. 2014. V. 118. N 4. P. 2138.

[5] Мирочник А.Г., Федоренко Е.В., Шлык Д.Х. // Изв. АН. Cep. хим. 2016. № 3. С. 806; Mirochnik A.G., Fedorenko E.V., Shlyk D.Kh. // Russ. Chem. Bull., Int. Ed., 2016. V. 65. N 3. P. 806.

[6] Espinoza J.D.A., Sazhnikov V., Smits E.C.P., Ionov D., Kononevich Y., Yakimets I. Alfimov M., Schoo H.F.M. // J. Fluoresc. 2014. V. 24. N 6. P. 1735. doi 10.1007/s10895-014-1462-4

[7] Fedorenko E.V., Mirochnik A.G., Lvov I.B., Vovna V.I. // Spectrochim. Acta Mol. Biomol. Spectrosc. 2014. V. 120. P. 119. doi 10.1016/j.saa.2013.10.016

[8] Farinola G.M., Ragni R. // Chem. Soc. Rev. 2011. V. 40. N 7. P. 3467. doi $10.1039 / \mathrm{c} 0 \mathrm{cs} 00204 \mathrm{f}$

[9] Wong W.-Y., Ho C.-L. // J. Mater. Chem. 2009. V. 19. N 26. P. 4457. doi 10.1039/b819943d

[10] Mukherjee S., Thilagar P. // Dyes Pigm. 2014. V. 110. P. 2. doi 10.1016/j.dyepig.2014.05.031

[11] Sarkar S.K., Kumar G.R., Thilagar P. // Chem. Commun. 2016. V. 52. N 22. P. 4175. doi 10.1039/c6cc00823b

[12] Карасев В.Е., Коротких О.А. // Журн. неорган. химии. 1986. T. 31. № 4. C. 869.

[13] Fedorenko E.V., Bukvetskii B.V., Mirochnik A.G., Shlyk D.H., Tkacheva M.V., Karpenko A.A. // JOL. 2010. V. 130. N 5. P. 756. doi 10.1016/j.jlumin.2009.11.027

[14] Казищына Л.А., Куплетская Н.Б. Применение УФ, ИК и ЯМР-спектроскопии в органической химии. Учебное пособие. М.: Высшая школа, 1971. 264 с. 